\title{
Association between self-reported dizziness and asymmetric hearing loss in the older adults
}

Ana Carla Oliveira Garcia ${ }^{1,2}$ https://orcid.org/0000-0003-4664-0073

Adrian Fuente ${ }^{2}$ https://orcid.org/0000-0003-3736-5057

Alejandro laniszewski ${ }^{2}$ https://orcid.org/0000-0002-9116-3969

Teresa Maria Momensohn dos Santos ${ }^{1}$ https://orcid.org/0000-0003-4751-0721

Pontifícia Universidade Católica de São Paulo - PUC/SP, São Paulo, São Paulo, Brasil.

Université de Montréal et Centre de Recherche de l'Institut Universitaire de Gériatrie de Montréal, Faculté de Médecine, École d'Orthophonie et d'Audiologie, Montreal, Canada.

Research support source: Coordenação de Aperfeiçoamento de Pessoal de Nível Superior - Brasil (CAPES).

Conflict of interests: Nonexistent

\section{(c) (i)}

Received on: January 7, 2019 Accepted on: December 18, 2019

Corresponding address: Ana Carla Oliveira Garcia

Rua Itapira, 219, Jardim Mesquita CEP: 12327-689 - Jacaré, São Paulo, Brasil

E-mail: anacarlagarciausa@gmail.com

\section{ABSTRACT}

Purpose: to verify the association between self-reported dizziness, degree and symmetry of hearing loss, age and gender in a sample of older adults.

Methods: this retrospective study included the analysis of 440 records of older adults with a mean age of 72.9 years, enrolled from 2011 to 2015 in an auditory rehabilitation service. Binary logistic regression models were performed between the variables, and the data was analyzed using the SPSS 24.00 software. For all tests, alpha values were considered significant when lower than 0.05 .

Results: in the sample, 78 (17.7\%) older adults had asymmetric hearing loss, and $27(34.6 \%)$ of them complained of dizziness. Self-reported complaint of dizziness was significantly associated with female gender $(p<0,001)$, to severe hearing loss $(p<0,001)$, age under 70 years, and with asymmetric hearing loss $(p<0,001)$.

Conclusion: in this study, younger female elderlies with severe asymmetric hearing loss presented self-reported complaint of dizziness . These results suggest that this population should be routinely screened for balance problems in order to provide rehabilitation programs to avoid future falls.

Keywords: Hearing; Dizziness; Elderly; Public Health 


\section{INTRODUCTION}

Age-related hearing loss is one of the three most prevalent chronic conditions in the elderly population, and it can interfere with their functional capacity ${ }^{1}$. According to the World Health Organization (WHO), approximately one third of the people over 65 years old are affected by hearing loss $^{2}$. As reported by the National Institute on Deafness and Other Communication Disorders (NIDCD), 30 to $35 \%$ of the elderly aged from 65 to 70 years exhibit some degree of hearing loss, and such percentage reaches 40 to $50 \%$ in individuals over 75 years ${ }^{3}$. In Brazil, studies show a prevalence of hearing loss among elderly ranging from $19.2 \%$ to $82.7 \%$, depending on the sample investigated and the diagnostic criteria used ${ }^{4}$. According to the Brazilian Institute of Geography and Statistics (Instituto Brasileiro de Geografia e Estatística - IBGE), the elderly population adds up to 23.5 million people, which suggests that the number of elderly with hearing loss can be more than $1,220,000$ people $^{5}$.

Some studies demonstrate that the prevalence of hearing loss is greater in men than in women. A study conducted by the National Health and Nutrition Examination Survey (NHANES) between 2011 and 2012, with population ranging from 20 to 69 years old, demonstrated that $39 \%$ of the people with hearing loss were between 60 and 69 years old, and that men were two times more likely to develop hearing loss than women ${ }^{6}$.

It is important to consider that dizziness is another very common symptom in the elderly population. Its prevalence described in the international literature varies considerably, with values ranging from $13 \%$ to $38 \%{ }^{7}$. An epidemiological study conducted in Brazil found a somewhat higher prevalence of dizziness in the elderly, of approximately $45 \%{ }^{8}$. A research conducted in 2015 with 63 elderly verified the association between dizziness and age-related hearing loss. The results suggested that dizziness could be associated with age-related hearing loss even in the absence of possible predisposing factors associated with vestibulopathy 9 . However, the study did not describe the prevalence of dizziness found. A retrospective study conducted from 2008 to 2011 which examined the medical records of 200 elderly patients, indicated that $74.5 \%$ of them complained of non-rotatory dizziness. Moreover, in $30 \%(n=60)$ of the sample, dizziness was associated with bilateral hearing loss ${ }^{10}$. However, less is known about the possible association between dizziness and the degree and asymmetry of the hearing loss. Also, it remains unclear whether the prevalence of dizziness varies between older women and older men with asymmetric hearing loss. This study constitutes an important epidemiologic tool which may help redefine public health policies, since previous studies demonstrate that elderly people with poorer auditory acuity exhibit greater risk of falls due to their reduced postural control ${ }^{11}$.

This study aimed at determining the possible relationship between self-reported complaint of dizziness, degree and symmetry of hearing loss, age and gender, in a sample of Brazilian elderly people.

\section{METHODS}

This research was approved by the Ethics Committee of the Pontifical Catholic University of São Paulo (Pontifícia Universidade Católica de São Paulo - PUC/SP) under Certificate of Presentation for Ethical Consideration (CAEE) number: 43831015.10000.5482. It is an analytical, descriptive, retrospective study, whose data collection was conducted by looking through medical records filed in the auditory rehabilitation service of the municipality of Jacareí, São Paulo, Brazil. According to the State Data Analysis System Foundation (SEADE 2016), Jacareí had approximately 223,207 inhabitants, among which approximately 31,409 people were 60 years old or over $(14.07 \%$ of the total population).

Four hundred and sixty-nine medical records which belonged to people who had registered in the auditory rehabilitation service were found. After applying the exclusion criteria filter, namely: age under 60 years; altered results in the acoustic immittance with types B, C, Ad, As curves; unilateral hearing loss and profound hearing loss which may not be associated to hearing loss related to age (presbycusis), 440 medical records were left to be analyzed. The elderly with the following criteria were included in the sample: a) those diagnosed with age-related hearing loss; $b$ ) with hearing thresholds in the frequency range from 250 to $8000 \mathrm{~Hz}$ greater than $25 \mathrm{~dB} \mathrm{HL}$; c) with a prescription to use a hearing aid (HA) provided by an Ear Nose and Throat specialist; and d) awaiting for the HA selection and fitting process.

The following data were collected from those 440 medical records: gender, age, pure-tone thresholds, tympanometry and self-reported complaints of dizziness. Classification of the audiograms based on degree of hearing loss was performed in accordance with Lloyd and Kaplan (1978) ${ }^{12}$, which described: 
pure-tone average $(0.5-2 \mathrm{kHz}) \leq 25 \mathrm{~dB} \mathrm{HL}$ (normal); 26 - $40 \mathrm{~dB} \mathrm{HL}$ (mild); 41 - $55 \mathrm{~dB} \mathrm{HL}$ (moderate); 56 - $70 \mathrm{~dB}$ HL (moderately severe); and, 71 - $90 \mathrm{~dB} \mathrm{HL}$ (severe). According to the criteria established by the Editorial Guidelines for description of inherited hearing loss ${ }^{13}$, a bilateral hearing loss was classified as asymmetric when there was a difference equal to or greater than $15 \mathrm{~dB} \mathrm{HL}$ between right and left ears in at least two continuous frequencies.

\section{Statistical analysis}

A chi-square test was used to determine possible associations between self-reported complaint of dizziness (yes/no), gender (female/male), symmetry of hearing loss (symmetric/asymmetric), and degree of hearing loss (mild, moderate, moderately severe and severe). Then, a logistic regression model was used between self-reported complaint of dizziness (dependent variable) and the independent variables (gender, age, degree and symmetry of hearing loss). The aim of this analysis was to determine the variables significantly associated with self-reported complaint of dizziness controlling by all the independent variables. Wald's test was used to determine the level of statistical significance for each independent variable. All independent variables were categorical. Thus, a reference category was selected for each variable. For gender, male was chosen as reference category; for age, people between 60 and 69 years old were considered as reference category; for symmetry of hearing loss, symmetric hearing loss was selected as reference category; and for degree of hearing loss, mild hearing loss was chosen as reference category. For all analyses, $p$-values smaller than 0.05 were considered significant. Statistical analyses were performed using SPSS 24.0 (SPSS Inc., Chicago, USA).

\section{RESULTS}

Figure 1 shows the flowchart of the sample after the application of the inclusion criteria to which all medical reports were submitted.

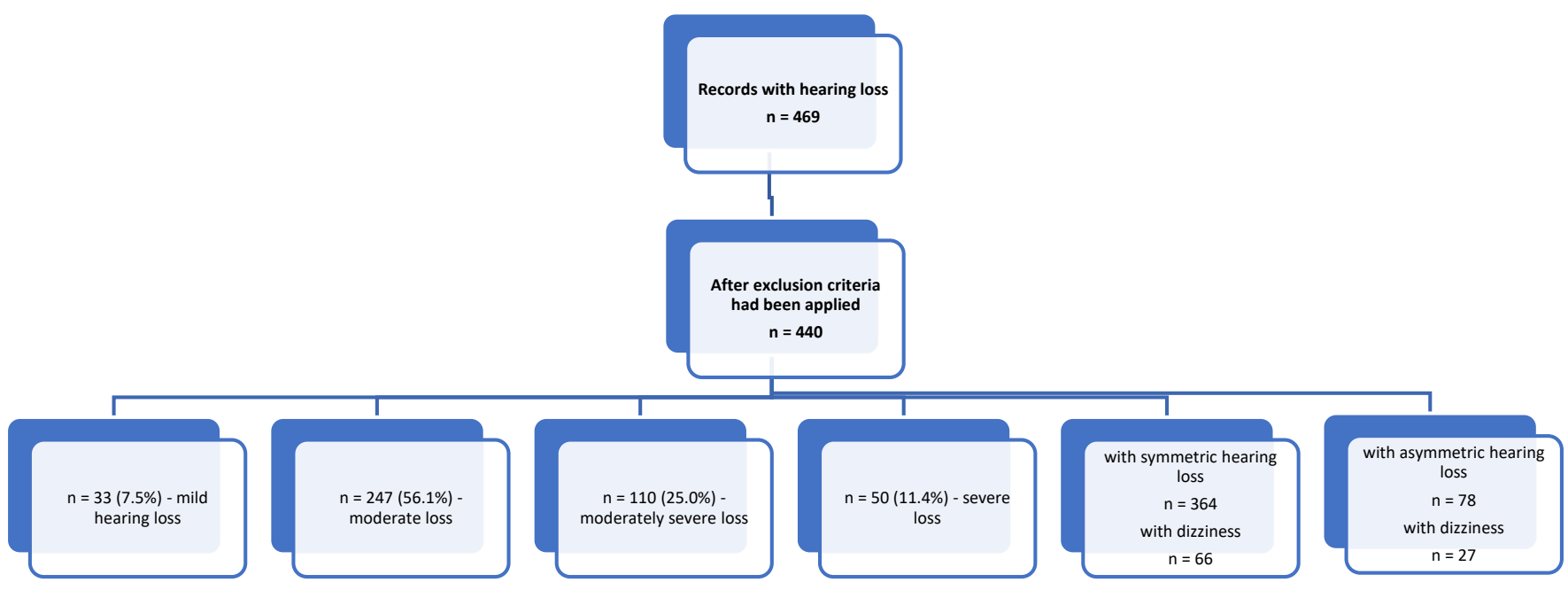

Figure 1. Flowchart with sample composition for this study

From all 469 collected medical records, 14 subjects with altered results in the acoustic immittance measures with types B, C, Ad, As curves; 7 medical records with unilateral hearing loss; and 8 medical records of elderly with profound hearing loss that may not be associated with age-related hearing loss (presbycusis) were excluded. The mean age of the selected group was of
72.9 years (minimum of 60 years and maximum of 94 years, standard deviation of 8.6 years).

From Table 1, it is noticed that, of the 280 female elderly, 83 (29.6\%) complained of dizziness. Of the 160 male elderly, on their part, $10(6.3 \%)$ complained of dizziness. Significant association was found between gander and self-reported complaint of dizziness $(p<0.001)$. 
Table 1. Combined frequency distribution between gender and self-reported complaint of dizziness (the percentages were calculated by gender) and $p$-value of the chi-square test of independence

\begin{tabular}{|c|c|c|c|c|c|c|}
\hline \multirow{3}{*}{ Gender } & \multicolumn{4}{|c|}{ Self-reported dizziness } & \multirow{2}{*}{\multicolumn{2}{|c|}{ Total }} \\
\hline & \multicolumn{2}{|c|}{ Yes } & \multicolumn{2}{|c|}{ No } & & \\
\hline & $\mathbf{N}$ & $\%$ & $\mathrm{~N}$ & $\%$ & $\mathrm{~N}$ & $\%$ \\
\hline Females & 83 & 29.6 & 197 & 70.4 & 280 & 100.0 \\
\hline Males & 10 & 6.3 & 150 & 93.7 & 160 & 100.0 \\
\hline Total & 93 & 21.1 & 347 & 78.9 & 440 & 100.0 \\
\hline
\end{tabular}

Legend: $\mathrm{N}=$ number of elderly people

In Table 2, the combined distribution of the elderly can be observed, regarding the degree of hearing loss and the self-reported complaint of dizziness. It is also observed that the percentage of elderly complaining of dizziness increases with the degree of hearing loss (12.1\% of the people with mild hearing loss presented dizziness, in comparation on with $42.0 \%$ of the people with severe hearing loss). There was evidence of statistically significant association between the self-reported complaint of dizziness and the degree of hearing loss $(p<0.001)$.

Table 2. Combined frequency distribution between degree of hearing loss and self-reported complaint of dizziness (the percentages were calculated by category of degree of loss) and p-value of the chi-square test of independence

\begin{tabular}{|c|c|c|c|c|c|c|}
\hline \multirow{3}{*}{ Degree of loss } & \multicolumn{4}{|c|}{ Self-reported dizziness } & \multirow{2}{*}{\multicolumn{2}{|c|}{ Total }} \\
\hline & \multicolumn{2}{|c|}{ Yes } & \multicolumn{2}{|c|}{ No } & & \\
\hline & $\mathrm{N}$ & $\%$ & $\mathbf{N}$ & $\%$ & $\mathrm{~N}$ & $\%$ \\
\hline Mild & 4 & 12.1 & 29 & 87.9 & 33 & 100.0 \\
\hline Moderate & 45 & 18.2 & 202 & 81.8 & 247 & 100.0 \\
\hline Moderately severe & 23 & 20.9 & 87 & 79.1 & 110 & 100.0 \\
\hline Severe & 21 & 42.0 & 29 & 58.0 & 50 & 100.0 \\
\hline Total & 93 & 21.1 & 347 & 78.9 & 440 & 100.0 \\
\hline
\end{tabular}

Legend: $\mathrm{N}=$ number of elderly people

Table 3 shows that, from the 78 elderly with asymmetric hearing loss, 27 (34.6\%) presented selfreported complaint of dizziness, whereas from the 362 elderly with symmetric hearing loss, only $66(18.2 \%)$ presented complaint of dizziness. The chi-square test of independence has shown a significant association between hearing loss symmetry and self-reported complaint of dizziness $(p<0.01)$.

Table 3. Combined frequency distribution between symmetry of hearing loss and self-reported complaint of dizziness (the percentages were calculated by category of symmetry of hearing loss) and p-value of the chi-square test of independence

\begin{tabular}{|c|c|c|c|c|c|c|}
\hline \multirow{3}{*}{ Symmetry of loss } & \multicolumn{4}{|c|}{ Dizziness } & \multirow{2}{*}{\multicolumn{2}{|c|}{ Total }} \\
\hline & \multicolumn{2}{|c|}{ Yes } & \multicolumn{2}{|c|}{ No } & & \\
\hline & N & $\%$ & $\mathbf{N}$ & $\%$ & N & $\%$ \\
\hline Symmetric & 66 & 18.2 & 296 & 81.8 & 362 & 100.0 \\
\hline Asymmetric & 27 & 34.6 & 51 & 65.4 & 78 & 100.0 \\
\hline Total & 93 & 21.1 & 347 & 78.9 & 440 & 100.0 \\
\hline
\end{tabular}

Legend: $\mathrm{N}=$ number of elderly people 
Table 4 presents the combined distribution of the elderly regarding age and the self-reported complaint of dizziness. It is noted that the percentage of elderly complaining of dizziness decreases with age $(28.6 \%$ of people under 70 years old presented dizziness, compared with $14.8 \%$ of those at least 80 years old). There was evidence of statistically significant association between self-reported complaint of dizziness and age $(p$-value $=0.012)$.

Table 4. Combined frequency distribution between age and self-reported complaint of dizziness (the percentages were calculated by category of degree of loss) and p-value of the chi-square test of independence

\begin{tabular}{|c|c|c|c|c|c|c|}
\hline \multirow{3}{*}{ Age } & \multicolumn{4}{|c|}{ Dizziness } & \multirow{2}{*}{\multicolumn{2}{|c|}{ Total }} \\
\hline & \multicolumn{2}{|c|}{ Yes } & \multicolumn{2}{|c|}{ No } & & \\
\hline & $\mathbf{N}$ & $\%$ & $\mathbf{N}$ & $\%$ & $\mathrm{~N}$ & $\%$ \\
\hline$<70$ years & 46 & 28.6 & 115 & 71.4 & 161 & 100.0 \\
\hline 70 to 79 years & 31 & 18.1 & 140 & 81.9 & 171 & 100.0 \\
\hline$\geq 80$ years & 16 & 14.8 & 92 & 85.2 & 108 & 100.0 \\
\hline Total & 93 & 21.1 & 347 & 78.9 & 440 & 100.0 \\
\hline & $1 ; p$ & 0.012 & & & & \\
\hline
\end{tabular}

Legend: $\mathrm{N}=$ number of elderly people

In the logistic regression model between the selfreported complaint of dizziness (dependent variable) and the independent age, gender, symmetry and degree of hearing loss variables, it was verified that the female gender, the severe degree of hearing loss, the asymmetric hearing loss and the age of 70 years or over were the statistically significant variables when adjusted by the other independent variables. The women have shown to be 26 times more likely to present dizziness than the men. The elderly with asymmetric hearing loss were four times more likely to manifest dizziness than the elderly with symmetric hearing loss. The elderly with severe hearing loss were six times more likely to present dizziness than the elderly with mild hearing loss. Lastly, the elderly between 60 and 69 years old were eight times more likely to present dizziness than those 70 years old or over.

Table 5 shows that the four independent variables are significant at the level of significance of $5 \%$.

Table 5. Results of the logistic regression between the self-reported complaint of dizziness and the age, gender, symmetry and degree of hearing loss variables

\begin{tabular}{|c|c|c|c|}
\hline Variables & Coefficient B & Wald test & $\mathrm{p}$-value \\
\hline Age 60-69 years & & Reference & \\
\hline Age 70 years or over & -0.75 & 8.72 & 0.003 \\
\hline Male gender & & Reference & \\
\hline Female gender & 1.87 & 26.97 & $p<0.0001$ \\
\hline Symmetric hearing loss & & Reference & \\
\hline Asymmetric hearing loss & 0.70 & 4.92 & 0.02 \\
\hline Mild hearing loss & & Reference & \\
\hline Moderate hearing loss & 0.72 & 1.55 & 0.21 \\
\hline Moderate to severe hearing loss & 0.66 & 1.17 & 0.27 \\
\hline Severe hearing loss & 1.57 & 6.06 & 0.01 \\
\hline
\end{tabular}




\section{DISCUSSION}

In this study, statistical analyses indicated significant associations between self-reported complaint of dizziness, gender (female), degree of hearing loss, symmetry of hearing loss, and age. Similar results were found in a longitudinal study conducted in Africa in 2014, which demonstrated a significant association between gender and self-reported complaint of dizziness in the elderly ${ }^{14}$. In addition, Carmo et al. in 2008 found that self-reported complaint of dizziness was significantly associated with gender (female). Tinetti et al. ${ }^{15}$ found a significant association between self-reported complaint of dizziness and hearing loss. However, self-reported complaint of dizziness did not associate with age or gender. Similar results were reported by Stevens et al. ${ }^{16}$, which found a significant association between selfreported complaint of dizziness and hearing loss in a group of elderly, but not with gender or age.

It is interesting to observe that, in the studies dealing with aging issues, it is difficult to find samples matched for gender. In most of the studies that were consulted, the number of women usually exceeded the number of men. Moreover, women comprise the majority of the older population in all regions of the world, living, in average, five to seven years longer than $\operatorname{men}^{17}$.

In this study, the presence of self-reported complaint of dizziness was greater in the elderly under 70 years. Similar results were reported by Nishino et al. ${ }^{18}$, which found that a $35.9 \%$ of elderly between 61 to 70 years complained of dizziness versus a $12.8 \%$ of elderly between 71 to 80 years.

There are many reasons for elderly under 70 years to report more complaints of dizziness than those older than that. First, factors such as stress, low (or bad) quality of life, self-attitude towards progressively appearing diseases and functional difficulties, excessive daily life activities among others ${ }^{19}$, may contribute to the onset of this symptom in the elderly. Second, emotional affective conflicts possibly attributed to working after retirement and/or grandchildren caring may also account for the high prevalence of selfreported complaints of dizziness in this population ${ }^{20}$. The accumulation of tasks associated with aging may trigger the onset of this symptom. Lastly, it is likely that elderly people over 70 years are able to compensate for their dizziness due to experience-dependent central neuroplasticity ${ }^{21}$. However, further studies about the interaction between the aforementioned factors and greater presence of dizziness in the elderly under 70 years are necessary.
This study demonstrated that the elderly with severe asymmetric hearing loss reported more complaints of dizziness when compared with those with mild and moderate hearing loss. Berge et al..$^{22}$ found a significant association between alterations in balance and degree of hearing loss in a group of elderly. To our knowledge, this is the first study to report a significant association between asymmetric hearing loss and self-reported complaint of dizziness in the elderly.

In the audiology clinic it is highly recommended that all asymmetric or unilateral hearing losses be carefully investigated $^{23}$, since asymmetric hearing loss can be both secondary to an aging process and/or associated with pathologies of the central auditory nervous system $^{24,25}$. It is important to remember that asymmetric hearing losses may require more care during the hearing aid fitting process, given that the auditory needs may differ for each ear. It is also important that these asymmetric hearing losses be better investigated from the clinical standpoint, for conditions needing medical interventions to be distinguished from those that need auditory rehabilitation.

High prevalence of dizziness was found in the elderly group assessed in this study. Valete-Rosalino ${ }^{26}$ conducted a prospective study in Brazil (indicate community) where 50 elderly between the ages of 60 and 80 years were interviewed. Results from that study indicated that dizziness was a prevailing symptom among the elderly from that community, along with the presence of comorbidities (48\%) and daily use of three or more medications (40\%). The presence of dizziness among them may be related to an alteration in the vestibular system. Age-related degeneration of different neural structures affects the vestibular system and, consequently, this population's balance. Such a degeneration occurs in the vestibular receptors, the central vestibular neurons, the cerebellum, and the proprioceptive and visual pathways. Studies show that the number of hair cells in the vestibular organs and the amount of fibers in the superior and inferior vestibular nerves decrease with age ${ }^{27}$.

It is necessary to consider that dizziness constitutes a risk factor for falls in the elderly population, and it can be thought of as a public health issue. As the elderly population grows in number, preventing falls and their inherent risks becomes a concern for the health professionals. In addition, the literature has shown that dizziness associated with hearing loss, becomes an even greater problem, causing more insecurity and loss of autonomy in this population. Dizziness can be 
the result of various diseases affecting an organism that has already been debilitated by its own natural deterioration, impairing the maintenance of body balance. The greater the number of associated diseases, the greater the risk of presenting dizziness, especially if such number is higher than three ${ }^{28}$.

Magrini and Momensohn-Santos ${ }^{29}$ analyzed and characterized the clinical and sociodemographic relations of elderly people with hearing loss and dizziness reference. Their results showed that $63.3 \%$ ( $n=95$ ) of the elderly complained of dizziness and that $54.7 \%(n=82)$ reported having a hearing loss. Regardless of the presence of dizziness, $65.3 \%(n=$ 98) reported not falling in the past 12 months. However, $60.7 \%(n=91)$ exhibited dizziness or balance-related difficulties in the previous 12 months $^{29}$.

The results from this study indicate that elderly people, especially those with asymmetric hearing loss, must be routinely screened for balance problems. It is important to consider that retrospective studies of secondary data, in themselves, limit the data collection, as the patients' records are often incompletely filled, or questions that would be of the researcher's interest were not made.

The fact that it is a retrospective survey on medical records with self-reported dizziness information limited this research, as in this study it was not possible to obtain information on other associated pathologies.

Another issue to be discussed refers to what the patient understands as dizziness; there may be some confusion concerning this terminology. Vertigo, instability and unbalance can be mistaken by the patient for dizziness. The misconceptions of the terms may have led to an overestimation or underestimation of this symptom in this population.

\section{CONCLUSION}

Considering the database analyzed, it was possible to find an association between self-reported dizziness and severe asymmetric hearing loss in elderly women under 70 years of age. These results suggest that treatment strategies targeting auditory problems in the elderly should carefully consider the singularity and specific characteristics of the population.

\section{ACKOWLEDGEMENT}

Gratitude is extended to the Coordination for the Improvement of Higher Education Personnel (CAPES, its Portuguese acronym) for the grant provided for this study.

\section{REFERENCES}

1. Moraes EM. Processo de envelhecimento e bases da avaliação multidimensional do idoso. In: Borges APA, Coimbra AMC (orgs). Envelhecimento e saúde da pessoa idosa. Rio de Janeiro: Fiocruz/ ENSP/EAD; 2008.p.151-75.

2. Organization $\mathrm{WH}$. International Classification of Functioning, Disability, and Health: Children \& Youth Version: ICF-CY. World Health Organization; 2007.

3. Disorders NloDaOC. Hearing loss prevalence declining in U.S. adults aged 20 to 69 years. National Institute on Deafness and Other Communication Disorders (NIDCD); 2016.

4. Baraldi GA, Almeida LC, Borges ACC. Evolução da perda auditiva no decorrer do envelhecimento. Rev. Bras. Otorrinolaringol. 2007;73(1): 64-70. http:// dx.doi.org/10.1590/S0034-72992007000100010

5. Síntese de indicadores sociais : uma análise das condições de vida da população brasileira : 2016 / IBGE, Coordenação de População e Indicadores Sociais. - Rio de Janeiro : IBGE, 2016146 p. (Estudos e pesquisas. Informação demográfica e socioeconômica, ISSN 1516-3296 ; n. 36).

6. Lin FR, Thorpe R, Gordon-Salant S, Ferrucci L. Hearing loss prevalence and risk factors among older adults in the United States. J Gerontol A Biol Sci Med Sci. 2011;66(5):582-90. doi: 10.1093/ gerona/glr002.

7. Gopinath B, McMahon CM, Rochtchina E, Mitchell $P$. Dizziness and vertigo in an older population: the Blue Mountains prospective cross-sectional study. Clin Otolaryngol. 2009;34(6):552-6. doi. org/10.1111/j.1749-4486.2009.02025.x.

8. Araujo TM, lório MCM. Profile of the elderly population referred for hearing aid fitting in a public hospital . Audiol., Commun. Res. 2014;19(1):45-51.

9. Helzner EP, Cauley JA, Pratt SR, Wisniewski SR, Zmuda JM, Talbott EO et al. Race and sex differences in age-related hearing loss: the health, aging and body composition study. J Am Geriatr Soc. 2005;53(12):2119-27. doi:10.1111/j.1532-5415.2005.00525.x.

10. Kasse CA, Onishi ET, Ganança MM, BrancoBarreiro FCA, Dona F, Gazzola J. Característica clínica de 200 idosos da comunidade com queixas vestibulares. Rev Bras Med. 2014;71(5):129-34. 
11. Gazzola JM, Freitas Ganança F, Aratani MC, Rodrigues Perracini M, Malavasi Ganança M. Caracterização clínica de idosos com disfunção vestibular crônica. BJORL. 2006;72(4):515-22.

12. Lloyd LL, Kaplan H. Audiometric interpretation: a manual of basic audiometry. Baltimore: University Park Press; 1978, Vol 1.

13. Parving A, Newton V. Guidelines for description of inherited hearing loss. J Audiol Med. 1995;4:2-5.

14. Lasisi AO, Gureje O. Prevalence, clinical and life-style correlate of dizziness among the community elderly from the ibadan study of agein. ENT Journal. 2014;93(0):E37-E44.

15. Tinetti ME, Williams CS, Gill TM. Dizziness among older adults: a possible geriatric syndrome. Annals of International Medicine. American College of Physicians. 2000;132(5):337-44. doi. org/10.7326/0003-4819-132-5-200003070-00002

16. Stevens KN, Lang IA, Guralnik JM, Melzer D. Epidemiology of balance and dizziness in a national population: findings from the english longitudinal study of ageing. Ageing. 2008;37(3):300-5.

17. Nicodemo D, Godoi MP. Juventude dos anos 60-70 e envelhecimento: estudo de casos sobre feminização e direitos de mulheres idosas. RCE. 2010;6(1):40-53.

18. Nishino LK, Ganança CdF, Manso A, Campos CAHd, Korn GP. Reabilitação vestibular personalizada: levantamento de prontuários dos pacientes atendidos no ambulatório de otoneurologia da ISCMSP. Rev Bras Otorrinolaringol. 2005;71(4):440-7.

19. Johnsson R, Sixt E, Landahl S, Rosenhall U. Prevalence of dizziness and vertigo in an urban elderly population. J Vestib Res. 2004;1(14):47-52

20. Fonseca SC. O Envelhecimento Ativo e seus Fundamentos . 1. ed.São Paulo. Portal Edições, Envelhecimento; 2016.

21. Woellner SS, Araujo AGS, Martins JS. Protocolos de equilíbrio e quedas em idosos. Neurociências. 2009;10(2):104-17.

22. Berge JE, Nordahl SHG, Aarstad HJ, Goplen FK. Hearing as an independent predictor of postural balance in 1075 patients evaluated for dizziness. 2019. Otolaryngol Head Neck Surg. 2019;161(3):478-84.

23. Mattos LC, Veras RP. A prevalência da perda auditiva em uma população de idosos da cidade do Rio de Janeiro: um estudo seccional. BJORL. 2007;73(5):654-9.
24. Martins K, Fontenele M, Camara S, Sartorato EL. Genetic and audio logic study in elderly with sensorineural hearing loss. CoDAS. 2013;25(3):224-8.

25. Prasad J, Cousins VC. Asymmetrical hearing loss. Aust Fam Physician. 2008;37(4):312-20.

26. Valete-Rosalino CM. Perda auditiva e tontura em idosos: medicamentos e outros fatores associados [Tese]. Rio de Janeiro (RJ): Escola Nacional de Saúde Pública Sergio Arouca, Escola Nacional de Saúde Pública da Fundação Oswaldo Cruz; 2005.

27. Merchant SN, Velazquez-Villasenor L, Tsuji K, Glynn RJ, Wall C III, Rauch SD. Temporal bone studies of the human peripheral vestibular system. Normative vestibular hair cell data. Ann Otol Rhinol Laryngol. 2000;181 (suppl):3-13.

28. Cruz MS, Lima MCP, Santos JLF, Duarte YAO, Lebrão ML, Ramos-Cerqueira ATA. Deficiência auditiva referida por idosos no município de São Paulo, Brasil: prevalência e fatores associados (Estudo SABE, 2006). Cad Saúde Pública. 2012;28(8):1479-92.

29. Magrini A, Momensohn-Santos T. A análise e a caracterização de uma população de idosos com perda auditiva e queixa de tontura. Rev. Kairós. 2019;22(1):353-65. 